\title{
Formation and characterization of carbon micro-spheres doped with boron and nitrogen
}

\author{
Hidetaka Konno**, Ryoko Matsuura*, Hajime Kiyono*, Akihiro Sudoh*, Hiroki Habazaki* and Michio Inagaki**
}

\begin{abstract}
Carbon micro-spheres doped with boron and nitrogen have been made from a chelate resin, in which $N$-methyl glucamate functional groups form ester with borate ions. Carbon spheres formed by heating at $1000-1600{ }^{\circ} \mathrm{C}$ for $1 \mathrm{~h}$ in argon were $140-340 \mu \mathrm{m}$ in diameter and the central ca. 1/3 of sphere was hollow. They contained 4.4-4.8 mass \% of boron, and B/C and N/C mole ratios of the sphere surface increased markedly with raising heat treatment temperature (HTT). Most of boron and nitrogen atoms in the surface layer of $1600{ }^{\circ} \mathrm{C}$ product were in the form of $>\mathrm{B}-\mathrm{N}<$ bonds. Hardness and elastic modulus including Poisson's ratio were highest for the spheres produced at $1000^{\circ} \mathrm{C}, 1.24 \mathrm{GPa}$ and $18.9 \mathrm{GPa}$, respectively, and decreased with raising HTT. Generally, oxidation resistance of spheres in pure oxygen increased with raising HTT, which may be owing to the increased amounts of surface $>\mathrm{B}-\mathrm{N}<$ bonds.
\end{abstract}

KEYWORDS : Carbon sphere, Carbon composites, Chelate resin, Mechanical properties, Oxidation resistance

\section{Introduction}

Doping of boron and nitrogen into carbon leads to the improvement and/or significant changes of chemical and physical properties, such as oxidation resistance, mechanical properties, electric conductivity, electrochemical properties, and so on ${ }^{1)}$. We reported preparation of boron containing polyimide films; carbonization and graphitization behavior of the films ; microstructure, boron/ nitrogen concentration, and electrical properties of formed carbon/ graphite $^{2)-4)}$. In the present work B/C/N composite micro-spheres were synthesized using a borate ion-selective chelate resin, and the structure, mechanical properties, and oxidation resistance were investigated.

\section{Experimental}

A chelate resin, Mitsubishi Chemical CRB02 (particle diameter $350-550 \mu \mathrm{m}$ ) was used. The resin is composed of the polystyrene frame structure cross-linked with divinylbenzene and has $N$-methyl glucamate functional groups, which form ester with borate ions as shown in Fig.1. About $100 \mathrm{~cm}^{3}$ of resin particles were stirred in $500 \mathrm{~cm}^{3}$ of $0.1 \mathrm{~mol} \mathrm{dm}-3 \mathrm{H}_{3} \mathrm{BO}_{3}$ solution for $3 \mathrm{~h}$ to form borate bearing chelate resin (referred to as CRB02-B). After filtration, they were vacuum dried at $120^{\circ} \mathrm{C}$ for $2 \mathrm{~h}$, and carbonized in a flow of argon at temperatures of $1000,1200,1400$ and $1600^{\circ} \mathrm{C}$ for $1 \mathrm{~h}$ : heating rate was $400 \mathrm{~K} \mathrm{~h}^{-1}$ for the former two and $300 \mathrm{~K} \mathrm{~h}^{-1}$ for

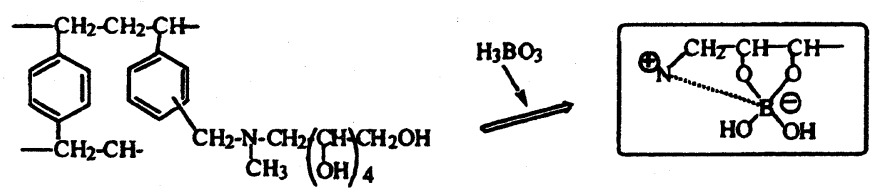

Fig.1 Frame structure of CRB02 chelate resin and a scheme of ester formation with boric acid.

the latter two, due to different furnaces used. Hereafter products are referred to as CRB02-B1200 and so on with heat treatment temperature (HTT). Unless additionally described, as-formed spheres were subjected to the following characterization.

To determine the boron content, CRB02-B and products were melted with $\mathrm{K}_{2} \mathrm{CO}_{3}$ and $\mathrm{Na}_{2} \mathrm{CO}_{3}$ in a Pt crucible, cooled to ambient temperature, and dissolved in conc. $\mathrm{HCl}$. The $\mathrm{HCl}$ solution obtained was diluted and analyzed for boron by inductively coupled plasma atomic emission spectrometry (ICP-AES, Shimadzu ICPS1000-IV). Conventional elemental analysis for carbon, nitrogen, and hydrogen was unsuccessful due to incomplete combustion. Carbonization behavior of CRB02 and CRB02-B was examined by thermogravimetry (TG, SEIKO TG/DTA32) up to $1000{ }^{\circ} \mathrm{C}$ at 400 $\mathrm{K} \mathrm{h}^{-1}$ in a flow of argon. Characterization of CRB02-B and products was carried out by scanning electron microscopy (SEM, JEOL JSM-5000, $10 \mathrm{kV}$ ), X-ray diffraction (XRD, Rigaku RAD-X RIND2000, $\mathrm{Cu} \mathrm{K} \alpha$ ), magic angle spinning nuclear magnetic resonance (MAS-NMR, Bruker MSL-300, spinning rate $3-3.5 \mathrm{kHz}$, resonance 
frequency $96.294 \mathrm{MHz}$ ) and X-ray photoelectron spectroscopy (XPS, VG ESCALAB MkII, Mg K $\alpha$ ). Surface composition of the products was estimated from the integral intensities of $B 1 \mathrm{~s}, \mathrm{C} 1 \mathrm{~s}$, and $\mathrm{N} 1 \mathrm{~s}$ spectra by XPS using relative sensitivity factors, $s_{\mathrm{N}} / s_{\mathrm{C}}=$ $1.75^{4), 5)}$ and $s_{\mathrm{B}} / s_{\mathrm{C}}=0.52^{4)}$. Details of XPS analysis are described in refs. 4) and 5).

The hardness and the elastic modulus including Poisson's ratio were measured using a Dynamic Ultra Micro Hardness Tester, DUH-W201S, by courtesy of Shimadzu Corporation. The measurements were carried out for the spheres of about $200 \mu \mathrm{m}$ in diameter under a load of $98 \mathrm{mN}$, where the indentation depth was less than about $2 \mu \mathrm{m}$. The values obtained for 5 samples were corrected in conformity with JIS Z 2244 and averaged.

Oxidation resistance was evaluated by TG up to $1000{ }^{\circ} \mathrm{C}$ at 400 $\mathrm{K} \mathrm{h}^{-1}$ in pure oxygen.

\section{Results and discussion}

Carbonization behavior of CRB02 and CRB02-B is shown in Fig.2. Apart from the detailed carbonization mechanism, the carbonization behavior of CRB02 is undoubtedly changed by ester formation with borate. The initial 2.5 mass \% of loss for CRB02-B up to $200{ }^{\circ} \mathrm{C}$ may be due to absorbed water, since profile of the curve does not fit with dehydration of borate. In addition, boron content of CRB02-B was 2.2 mass \%, which corresponded to 9.1 mass $\%$ of $=\mathrm{B}(\mathrm{OH})_{2}$ groups (see Fig.1), and dehydration from this borate species should amount to 3.7 mass \% of loss. Net yield of carbonaceous material from CRB02-B at $1000{ }^{\circ} \mathrm{C}$ is about 25 mass \% (Fig.2) and so the expected boron content of the products will be larger than 8 mass \%. As described later, however, the analyzed boron content was $4.4-4.8$ mass $\%$ for all the products (Fig.7), that is, nearly half of boron atoms in the resin disappeared on carbonization. These results suggest that CRB02-B is

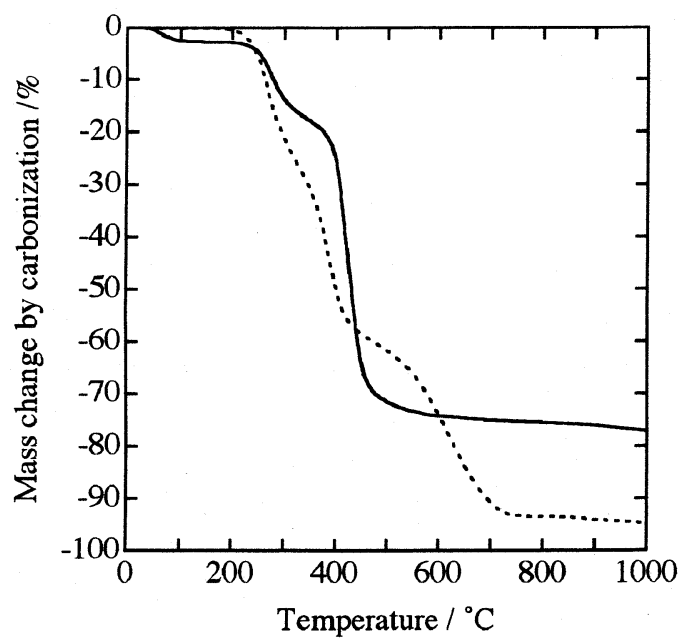

Fig.2 Thermogravimetric curves of CRB02 (broken line) and CRB02-B (solid line) at $400 \mathrm{~K} \mathrm{~h}^{-1}$ in argon. carbonized in the form of ester and does not decompose separately as resin and borate, up to $1000{ }^{\circ} \mathrm{C}$ at least.

A photograph of formed carbon micro-spheres by SEM and the size distribution of CRB02-B1200 measured by a digital microscope are shown in Fig.3. The products were spheres of mostly $160-240 \mu \mathrm{m}$ in diameter and the central ca. 1/3 was hollow. The outer surface of spheres was smooth but the inner surface was porous similar to the carbon spheres produced from metal-bearing chelate resins ${ }^{6), 7)}$. The structure is resulted from gas evolution by thermal decomposition of resin.

The XRD patterns of crushed carbon spheres are shown in Fig.4 (b)-(d) together with uncrushed CRB02-B1000, Fig.4 (a). Slight development of turbostratic structure is observed for the products at higher HTT. The C 002 peak was sharp and stronger for uncrushed spheres, though the patterns are not shown in Fig.4. This suggests that the extent of carbonization is higher in the outer part of sphere than the inner part. Weak diffraction peaks of $\mathrm{B}_{2} \mathrm{O}_{3}$ were observed only for crushed CRB02-B1000 (Fig.4 (b)), and that no diffraction peaks of $\mathrm{B}_{2} \mathrm{O}_{3}$ for uncrushed one (Fig.4 (a)). The results indicate that appreciable amounts of crystalline $\mathrm{B}_{2} \mathrm{O}_{3}$ are formed only inside of CRB02-B1000 spheres. The ${ }^{11} \mathrm{~B}$ MAS-NMR spectra are shown in Fig.5, in which standard spectra for $\mathrm{B}_{2} \mathrm{O}_{3}$ and $\mathrm{B}_{4} \mathrm{C}$
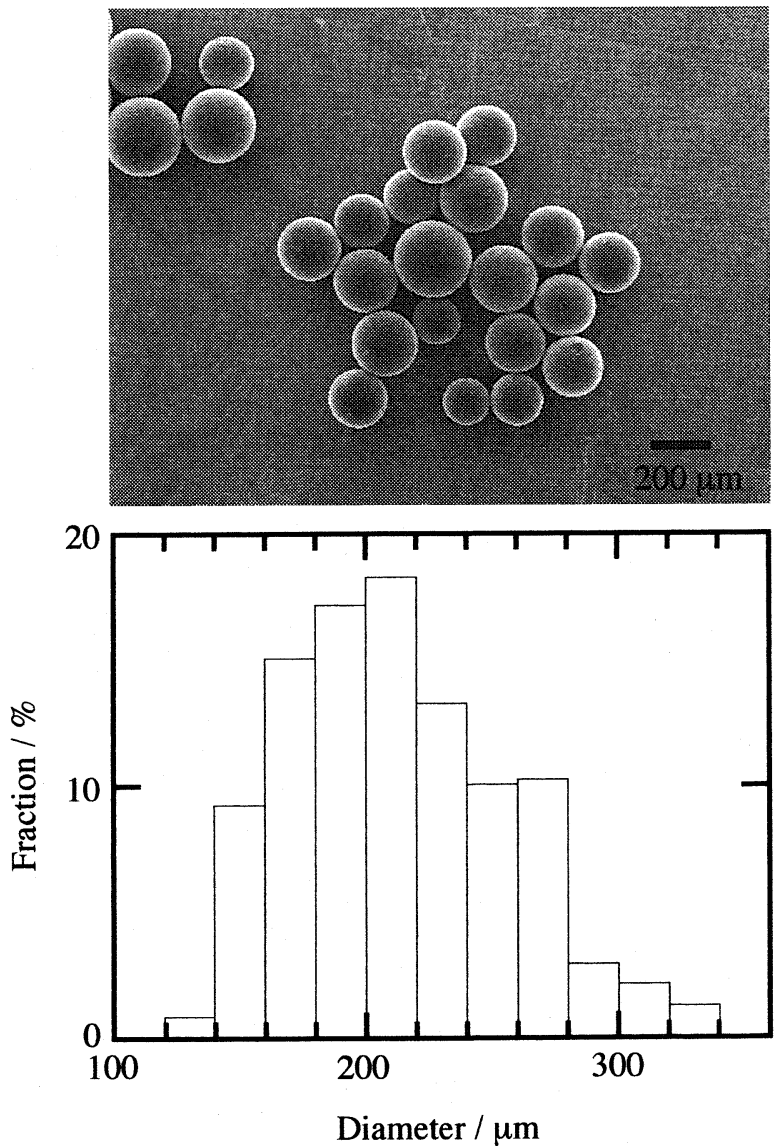

Fig.3 SEM photograph of CRB02-B1000 and the size distribution by direct measurements of 479 particles by a digital microscope. 


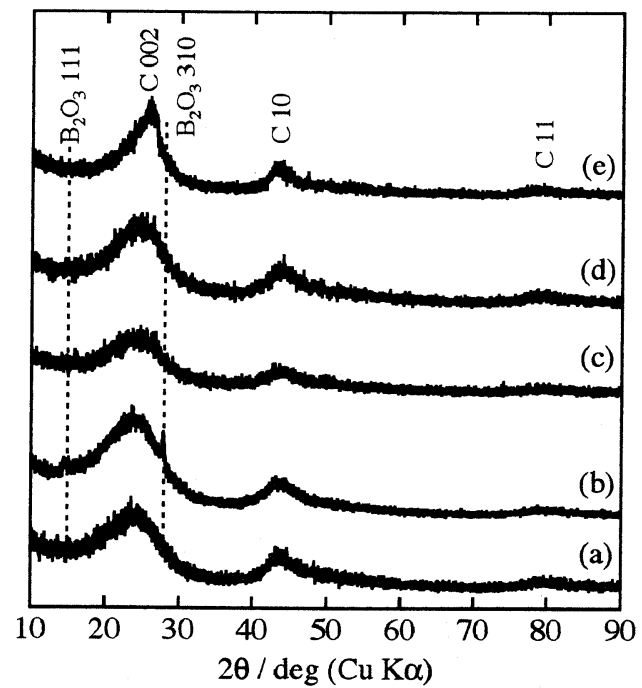

Fig.4 XRD patterns of uncrushed (a) CRB02-B1000 and crushed (b) CRB02-B1000, (c) CRB02-B1200,-(d) CRB02-B1400, and (e) CRB02-B1600.

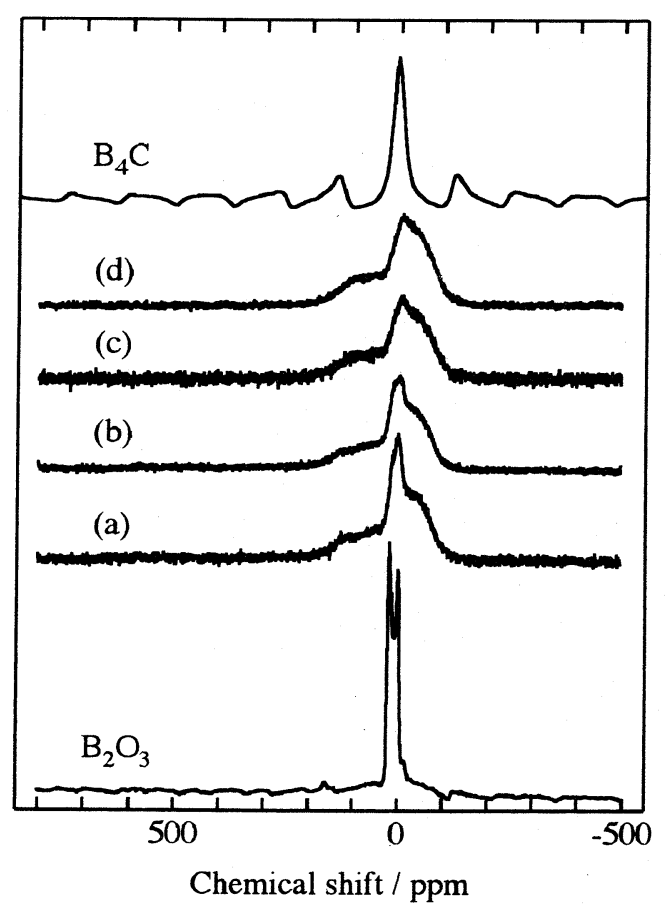

Fig.5 ${ }^{11} B$ MAS-NMR spectra of (a) CRB02-B1000, (b) CRB02B1200, (c) CRB02-B1400, and (d) CRB02-B1600.

are added for reference. A sharp peak around 0 ppm for CRB02B1000 (Fig.5 (a)) is assigned to $\mathrm{B}_{2} \mathrm{O}_{3}$ in agreement with the XRD pattern (Fig.4 (b)). A weak peak of $\mathrm{B}_{2} \mathrm{O}_{3}$ is observed also for CRB02-B1200 (Fig.5 (b)), though no diffraction peaks were distinguishable in the XRD pattern (Fig.4 (c)) . As no side bands are present in all the spectra, $\mathrm{B}_{4} \mathrm{C}$ is not formed in the carbon spheres. Broad peaks at around $+100 \mathrm{ppm}$ and $-100 \mathrm{ppm}$ are not assigned to known compounds but may be due to different B-C and B-N bonds, which is supported by the results of XPS measurements. In Fig.6, XPS spectra of B 1s and N 1s for
B 1s

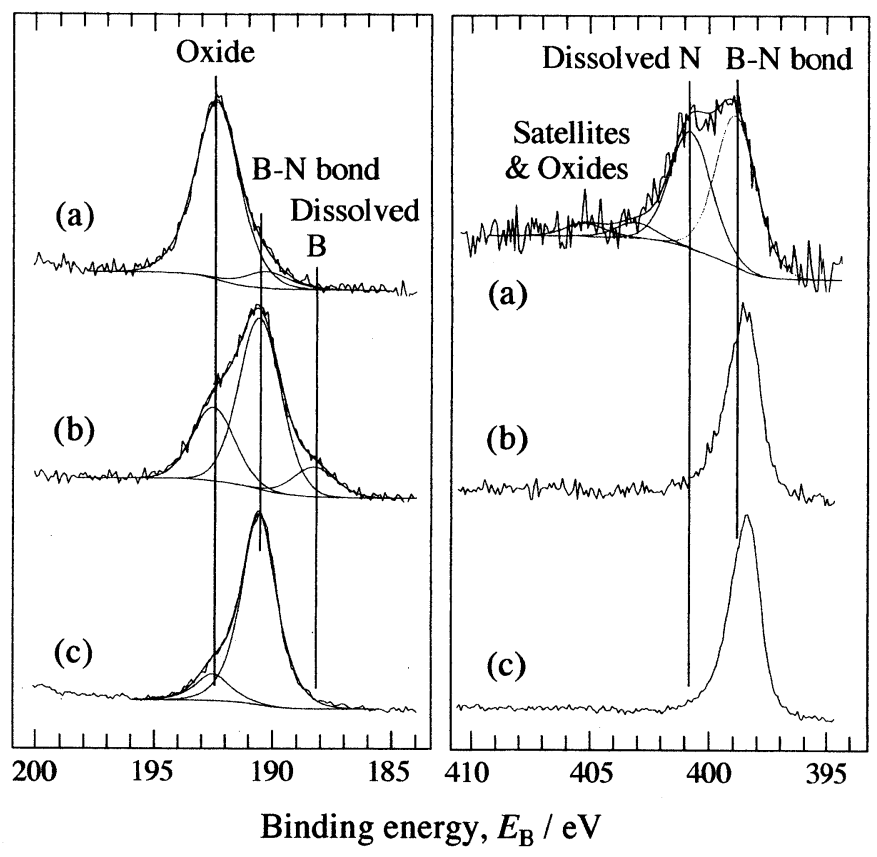

Fig.6 XPS spectra of (a) CRB02-B1000, (b) CRB02-B1400, and (c) CRB02-B1600.

uncrushed CRB02-B1000, CRB02-B1400, and CRB02-B1600 are shown. Three components are distinguishable for boron; dissolved boron $\left.\left.\left(E_{\mathrm{B}}=188 \mathrm{eV}^{3)}, 4\right), 8\right)\right),>\mathrm{B}-\mathrm{N}<$ bonds in the hexagonal carbon structure $\left.\left(E_{\mathrm{B}}=190 \mathrm{eV}^{3}\right), 4\right)$, and boron oxide $\left.\left(E_{\mathrm{B}}=192-193 \mathrm{eV}^{3}\right), 4\right)$. Relative intensity of boron oxide peak decreases with raising HTT, and inversely that of $>\mathrm{B}-\mathrm{N}<$ bonds peak increases. These results suggest that 1000 and $1200{ }^{\circ} \mathrm{C}$ products contained $\mathrm{B}_{2} \mathrm{O}_{3}$ both in the bulk and on the surface. As reported previously, when both boron and nitrogen are dissolved in the hexagonal carbon layer, B-N bonding makes the total energy minimum ${ }^{2)}$. The $\mathrm{N} 1 \mathrm{~s}$ spectrum for CRB02-B1000 is similar to that of boron-doped Kapton film carbonized at $1000{ }^{\circ} \mathrm{C}$ ) , but that for CRB02-B1400 and CRB02-B1600 is totally assigned to $>$ B-N $<$ bonds $\left.\left(E_{\mathrm{B}}=399 \mathrm{eV}^{3)}, 4\right), E_{\mathrm{B}}=398 \mathrm{eV}^{9}\right)$. The electron binding energies of $>\mathrm{B}-\mathrm{N}<$ bonds are shifting slightly with raising HTT; $E_{\mathrm{B}}[\mathrm{N} 1 \mathrm{~s}]$ shifts to lower energy side and $E_{\mathrm{B}}[\mathrm{B} 1 \mathrm{~s}]$ to higher side. In other words, these binding energies shift toward those in boron nitride $\left(E_{\mathrm{B}}[\mathrm{N} 1 \mathrm{~s}]=398.1 \mathrm{eV}\right.$ and $\left.E_{\mathrm{B}}[\mathrm{B} 1 \mathrm{~s}]=190.5 \mathrm{eV}^{10)}\right)$. This is probably due to (1) decreasing amounts of electronegative oxygen species and increasing amounts of $>\mathrm{B}-\mathrm{N}<$ bonds in the surface layer of carbon spheres with HTT, and (2) the development of hexagonal layer structure on the surface. The B/C and N/C mole ratios estimated from peak intensities are shown in Table 1, indicating that the amounts of boron and nitrogen on the surface increase with raising HTT. By using ratios of peak area in Fig.6 and the values in Table 1, relative amounts of $>$ B-N $<$ bonds to carbon are estimated from both B $1 \mathrm{~s}$ and $\mathrm{N} 1 \mathrm{~s}$ spectra, separately. The both spectra gave consistent results, 0.063 for CRB02-B1400, 
Table 1 Surface composition of spheres by XPS in mole ratio.

\begin{tabular}{cll}
\hline Products & $\mathrm{B} / \mathrm{C}$ & $\mathrm{N} / \mathrm{C}$ \\
\hline CRB02-B1000 & 0.051 & 0.024 \\
CRB02-B1400 & 0.099 & 0.068 \\
CRB02-B1600 & 0.22 & 0.20 \\
\hline
\end{tabular}

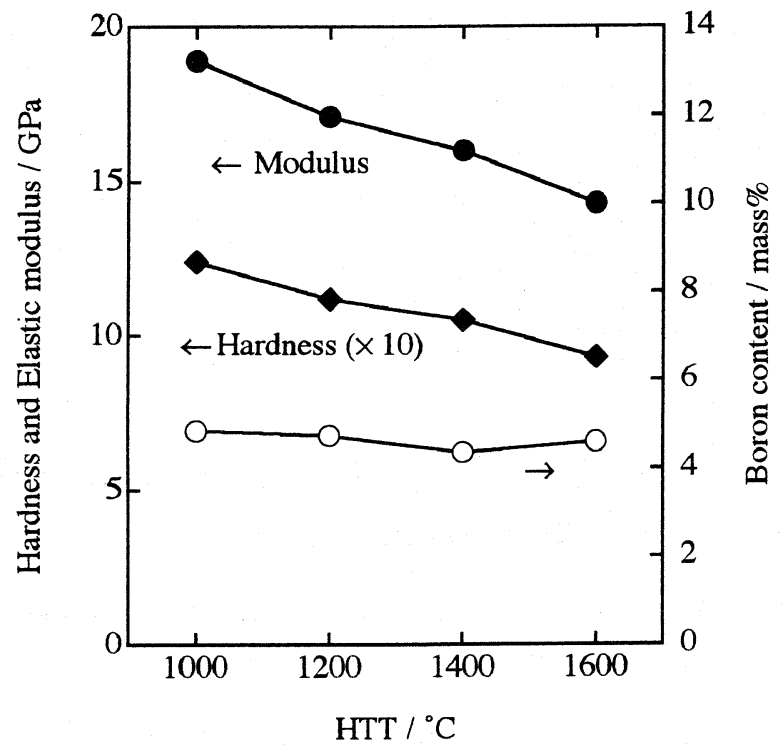

Fig.7 Boron content and mechanical properties of the products as a function of HTT.

and 0.20 for CRB02-B1600, but the values for CRB02-B1000 were inconsistent due to the predominant boron oxide peak and noisy $\mathrm{N}$ 1s spectrum $(\mathbf{F i g . 6}(\mathrm{a}))$. The surface concentration of $>\mathrm{B}-\mathrm{N}<$ bonds for CRB02-B1600 is anomalously high considering the nitrogen content of the resin used (Fig.1). Such increment of $>$ B-N $<$ bonds was observed also for the boron-doped graphite heat treated at $2000-2800{ }^{\circ} \mathrm{C}$ and $E_{\mathrm{B}}[\mathrm{N} 1 \mathrm{~s}]$ of $>\mathrm{B}-\mathrm{N}<$ bonds was about $398 \mathrm{eV}^{9)}$ similar to that for CRB02-B1600 (Fig.6 (c)). In that case ${ }^{9}$, only possible source of nitrogen was air occluded in raw materials during packing into graphite crucible. Such small amounts must be taken into account when boron content is an order of percent and high HTT is applied. Analyzed total boron content in the carbon sphere is shown as a function of HTT in Fig.7. It slightly decreases with HTT but practically the difference is not large.

The hardness and the elastic modulus including Poisson's ratio of spheres are shown in Fig.7, where \pm 1 standard deviation of data is comparable to or smaller than the size of symbols. The hardness and the modulus decrease with raising HTT but it is reasonably concluded that the bulk concentration of boron cannot be related to these two mechanical properties. It also suggests that, when CRB02-B is carbonized, the development of turbostratic structure does not lead to improving mechanical properties. The spheres of original resin carbonized at $1000{ }^{\circ} \mathrm{C}$ (referred to as CRB02-1000)

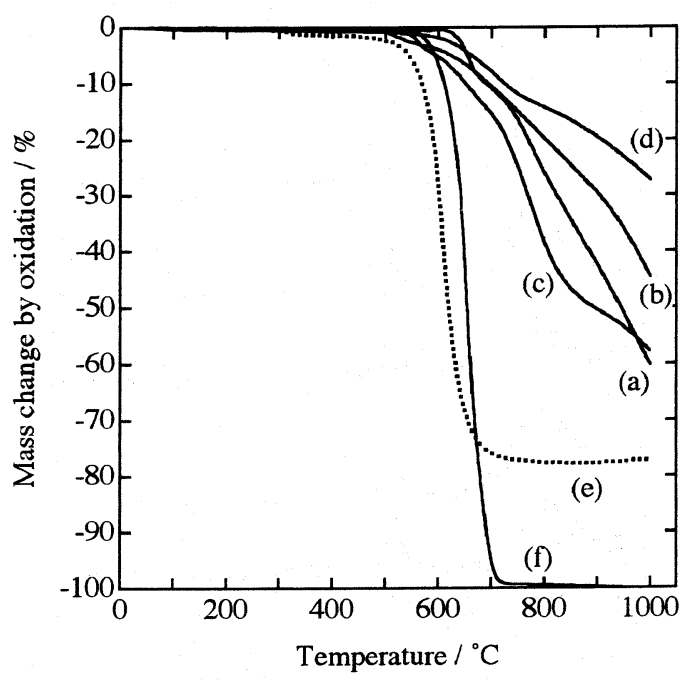

Fig.8 Oxidation test in pure oxygen at $400 \mathrm{~K} \mathrm{~h}^{-1}$ : (a) CRB02B1000, (b) CRB02-B1200, (c) CRB02-B1400, (d) CRB02B1600, (e) crushed CRB02-B1600, and (f) CRB02 resin carbonized at $1000{ }^{\circ} \mathrm{C}$ for $1 \mathrm{~h}$.

were much more fragile and easily crushed, indicating that the doped boron plays an important role in the improvement of mechanical properties as reported previously ${ }^{11), 12)}$. It is not appropriate to conclude without direct evidences but the following deduction may be admitted based on the experimental results, (1) there is no interrelation between the boron content and mechanical properties (Fig.7), and (2) boron oxide species on the surface and in the bulk of sphere decrease with raising HTT by XRD (Fig.4), MAS-NMR (Fig.5) and XPS (Fig.6): the mechanical properties may depend on the chemical state of boron in the carbon sphere, that is, the B-O bonds may have more favorable effect to them than B-C and/or B-N bonds. The hardness of CRB02-B1000 was 1.24 $( \pm 0.03) \mathrm{GPa}$, and comparable to that of $\mathrm{LiF}$ or $1 / 7-1 / 8$ that of fused quartz. Actually, these carbon spheres are hard to crush with an agate pestle and motor, and the cross-section is shiny similar to glass-like carbon. The results indicate that CRB02-B1000 has fairly good mechanical property.

The oxidation curves of carbon spheres in pure oxygen are shown in Fig.8 (a) - (d), where the results for crushed CRB02B1600 (Fig.8 (e)) and uncrushed CRB02-1000 (Fig.8 (f)) are also shown. The CRB02-1000 burns out completely around $700{ }^{\circ} \mathrm{C}$ as ordinary carbon materials. The curve for CRB02-B1400 is irregular but generally the products at higher HTT show better oxidation resistance. After crushing, however, all the products burned quickly above $600{ }^{\circ} \mathrm{C}$ and the final loss was around 80 mass \% as shown for CRB02-B1600, for example. Color of the residues after oxidation test was not white as expected to $\mathrm{B}_{2} \mathrm{O}_{3}$ but dark gray or black, even for crushed CRB02-B1600. There is a sign for crushed CRB02B1600 that once decreased mass increases from around $900{ }^{\circ} \mathrm{C}$ $($ Fig.8 (e)), implying that the further oxidation of boron components 
is taking place. The results in Fig.8 and the analytical data described above suggest that the chemical state of boron is a primary factor to improve oxidation resistance. The total boron content in the sphere is not different for all the products but the chemical state of boron on the surface is different by HTT. The $\mathrm{B}_{2} \mathrm{O}_{3}$ contributes to the oxidation resistance but it is not a crucial factor for the carbon spheres formed in the present work, since all the data indicate the decrease of $\mathrm{B}_{2} \mathrm{O}_{3}$ with raising HTT. The amounts of surface $>\mathrm{B}-\mathrm{N}<$ bonds correlate more significantly with the oxidation resistance, which is reinforced by poor oxidation resistance of the crushed spheres (Fig.8 (e) for example). Anomalous behavior of CRB02B1400 was reproducible and observed also by isothermal oxidation tests. It is difficult to give luscious explanations at present, but there is a possibility that dissolved boron exposed on the surface Fig.6 (b)) is related to the irregular oxidation behavior.

\section{Summary}

A commercial chelate resin, which has $N$-methyl glucamate functional groups and is selective to borate ions through ester formation, was reacted in a boric acid solution. Borate bearing resin particles were carbonized at $1000-1600{ }^{\circ} \mathrm{C}$ for $1 \mathrm{~h}$ in argon. Formed carbon spheres were $140-340 \mu \mathrm{m}$ in diameter and the central ca. $1 / 3$ of sphere was hollow. Results of characterization for the products are summarized as follows:

(1) The 1000 and $1200{ }^{\circ} \mathrm{C}$ products contained $\mathrm{B}_{2} \mathrm{O}_{3}$ in the bulk

(by XRD and MAS-NMR) and on the surface (by XPS).

(2) The spheres contained 4.4-4.8 mass \% of boron (by ICP$\mathrm{AES}$ ), and $\mathrm{B} / \mathrm{C}$ and N/C mole ratios in the surface layer of the sphere increased markedly with raising HTT.

(3) The amounts of surface $>\mathrm{B}-\mathrm{N}<$ bonds increased with raising HTT, and most of boron and nitrogen atoms in the surface layer of $1600{ }^{\circ} \mathrm{C}$ product were in the form of $>\mathrm{B}-\mathrm{N}<$ bonds. The BN compounds, however, were not detected by XRD and MAS-NMR.

(4) The hardness and the elastic modulus including Poisson's ratio were highest for the spheres produced at $1000{ }^{\circ} \mathrm{C}, 1.24 \mathrm{GPa}$ and $18.9 \mathrm{GPa}$, respectively, and decreased with raising HTT.

(5) Generally, the oxidation resistance of spheres in pure oxygen increased with raising HTT, and correlated more significantly with the amounts of surface $>\mathrm{B}-\mathrm{N}<$ bonds than that of $\mathrm{B}_{2} \mathrm{O}_{3}$.

The properties of carbon spheres produced in the present work should be improved more, but suggest potential usefulness for micro-components.

\section{Acknowledgment}

This work was partly supported by "The Research for the Future Program" of JSPS (JSPS-RFTF 96R11701).

\section{References}

1) e. g. M. Endo, T. Hayashi, Y. A. Kim, H. Ohota and S. W. Hong, Carbon Alloys (E. Yasuda, M. Inagaki, K. Kaneko, M. Endo, A. Oya and Y. Tanabe, eds.) (2003) Chap. 3, Elsevier, Oxford; T. Nakajima, ibid. Chap. 21.

2) H. Konno, H. Oka, K. Shiba, H. Tachikawa and M. Inagaki, Carbon 37 (1999) 887-895.

3) H. Konno, K. Shiba, Y. Kaburagi, Y. Hishiyama and M. Inagaki, Carbon 39 (2001) 1731-1740.

4) H. Konno, K. Shiba, H. Tachikawa, T. Nakahashi, H. Oka and M. Inagaki, Synthe. Met. 125 (2002) 189-196.

5) H. Konno and M. Inagaki, Anal. Sci. 15 (1999) 799-801.

6) F. Goutfer-Wurmser, H. Konno, Y. Kaburagi, K. Oshida and M. Inagaki, Synthe. Met. 118 (2001) 33-38.

7) H. Konno, R. Matsuura, M. Yamasaki and H. Habazaki, Synthe. Met. 125 (2002) 167-170.

8) T. Shirasaki, A. Derré, M. Ménétrier, A. Tressaud and S. Flandrois, Carbon 38 (2000) 1461-1467.

9) H. Konno, T. Nakahashi, M. Inagaki and T. Sogabe, Carbon 37 (1999) 471-475.

10) D. Briggs and M. P. Seah, Practical Surface Analysis (Second Edition) (1990) p.599, John Wiley, New York.

11) T. Sogabe, K. Nakajima and M. Inagaki, J. Mater. Sci. 31 (1996) 6469-6476.

12) T. Sogabe, O. Okada, K. Kuroda and M. Inagaki, Carbon 35 (1997) 67-72. 